Systematic observation of, and simple experiment on, animals behaving in their natural habitat, so extensively developed by the 'ethological' school, has formed the natural and fruitful complement to laboratory studies. The theoretical formulations of this school have proved less rigid than they initially appeared to be, and much may be expected by crossfertilization between laboratory, and field, observation.

The possibilities of experiment on human beings are, however, not being neglected, and Prof. Oldfield gives one example, from the field of speech and language, where a fresh theoretical approach and new technical resources have led to rapid progress, with extension into other topics such as attention, where a century ago effective quantitative experiment would scarcely have been thought possible.

In concluding, Prof. Oldfield makes a number of observations about the prospects of experimental psychology. The most important factors making for good progress in the immediate future he believes are avoidance of parochialism, full and free collaboration between psychologists and workers in other relevant fields, the attraction of more young people of first-class ability into the subject and the provision of the right atmosphere for them to learn in as undergraduates and as graduate research students. He thinks that the future of the subject will be that of a biological discipline, destined one day, perhaps, to be instrumental in extending the present range of fundamental biological conceptions. The next hundred years promise exciting developments. But, feeling that there is little present evidence of any real wish on the part of human beings to understand themselves, he is unwilling to predict what their impact on people generally may be.

\section{ORIGIN OF ANGIOSPERMS}

A TTENTION was directed by Prof. T. M. Harris, in his presidential address to Section K (Botany), to the fact that fossil botanists have had notable success in bringing ancient plants to light, when they happened to have good material to study. They have been much less successful when they have directed their research to answer a specific question. Their longest sustained effort has been to discover the early ancestors of the flowering plants (Angiosperms), and here they have failed almost completely. The main thing that can be claimed on the credit side from much devoted research is that the fossils which they hoped they would be able to establish as ancestral flowering plants have been proved to be so different that no one now so regards them. Instead, they are representatives of extinct and strangely organized plant families. Progress has been made, but not in the way intended.

Unequivocal knowledge of some early flowering plants would not only satisfy the fossil botanists' desires; it would also have a profound effect on the botany of living plants. In two plant groups, the ferns and the conifers, the right sort of information is at hand from fossils; instead of interminable discussion there is simple agreement on the numerous botanical problems where the fossils tell a clear story.
In fact, little more is known now about the fossil history of flowering plants than in 1860 , but what was a doubtful boundary of knowledge then is now a clear boundary. It was then known that fossil flowering-plant organs, leaves, wood, fruits, seeds were common throughout the Tertiary period and as far back as the Cretaceous period, but they ceased rather after the Middle Cretaceous. Before that there were plenty of ferns, conifers and other plants, but very few that suggested a flowering plant. Those few which did suggest one were afterwards taken up enthusiastically for study and shown to be nothing of the sort. Fach decade has provided one or two new candidates, and most have since been rejected as the result of much hard work.

Fifty or a hundred years ago it was suggested that the flowering plants evolved in remote and geologically unexplored regions, perhaps near the North Pole, or perhaps on an isolated island, like New Zealand. Then, in the Cretaceous, geographical changes allowed them to escape and to spread over the Earth's surface and presently to exterminate most of the previous flora. As more is learnt, this kind of explanation becomes less likely; there is evidence now, for example, that the flowering plants arose at about the same time and in much the same manner in New Zealand as in Britain. There is, indeed, a current idea that they dominated the land a little earlier in the tropics than in high latitudes ; but it is not yet agreed where the Cretaceous poles and tropics lay. There is, too, a current theory that they evolved first in dry and upland regions, the fossils of which are seldom preserved. These theories are, in part, excuses for failure and what is needed more than excuses is a hypothesis which is a recipe, if not for success, at least for vigorous work. It seems, too, that the days of these theories may be numbered now that fossil-pollen is being so widely studied. Pollen blows far, and if the flowering plants were anywhere in force before the Cretaceous it should be possible to find their pollen. So far', what is known is that their kind of pollen appcars and increases at the same time as the leaves, or only a little earlier. Before the Cretaceous, there are a few claims for flowering-plant pollen grains, but then there are a few debatable leaves and other organs.

A hypothesis that does make for progress is that the ancestors of the flowering plantis were present in the regions that have been studied and that they have been collected, but they have been unrecognized because they are not like modern flowering plants and have been wrongly classified. Anyone looking at a fossil flora where everything is neatly classified might think this preposterous ; but, in fact, nearly all fossil genera are based on a single kind of organ known in isolation. Its classification is not secure, but merely tenuous reasoning from very scanty evidence. The genera of the text-books are the minute percentage of fully known ones.

These early fossils should be studied, not as early angiosperms, for that is to invite disappointment, but for whatever can be learnt about them. The new facts will provide surprises; that is, sometimes things will be found so new as to be contrary to expectation. Prof. Harris pointed out that nothing is more contrary to his own expectations when he studies a little-known fossil of pre-Cretaceous age that it will prove to be a flowering plant, but since it is almost unknown almost anything may happen : therein lies hope. 